COUNSELLING AND PSYCHOTHERAPY

IN PRIMARY HEALTH CARE 


\section{BASIC TEXTS IN COUNSELLING AND PSYCHOTHERAPY}

Series Editor: Stephen Frosh

This series introduces readers to the theory and practice of counselling and psychotherapy across a wide range of topic areas. The books will appeal to anyone wishing to use counselling and psychotherapeutic skills and will be particularly relevant to workers in health, education, social work and related settings.

The books in this series are unusual in being rooted in psychodynamic and systemic ideas, yet being written at an accessible, readable and introductory level. Each text offers theoretical background and guidance for practice, with creative use of clinical examples.

\section{Published}

Jenny Altschuler

WORKING WITH CHRONIC ILLNESS

Paul Terry

COUNSELLING THE ELDERLY AND THEIR CARERS

Jan Wiener and Mannie Sher

COUNSELLING AND PSYCHOTHERAPY IN PRIMARY HEALTH CARE

\section{Forthcoming}

Sheila Ernst, Bill Barnes and Keith Hyde

AN INTRODUCTION TO GROUPWORK

\section{Gill Gorell Barnes}

FAMILY THERAPY IN CHANGING TIMES

\section{Series Standing Order}

If you would like to receive future titles in this series as they are published, you can make use of our standing order facility. To place a standing order please contact your bookseller or, in case of difficulty, write to us at the address below with your name and address and the name of the series. Please state with which title you wish to begin your standing order. (If you live outside the UK we may not have the rights for your area, in which case we will forward your order to the publisher concerned.)

Standing Order Service, Macmillan Distribution Ltd, Houndmills, Basingstoke, Hampshire, RG21 6XS, England 


\title{
COUNSELLING AND PSYCHOTHERAPY IN Primary Health CARE
}

A Psychodynamic Approach

\author{
JAN Wiener \\ and \\ Mannie Sher
}

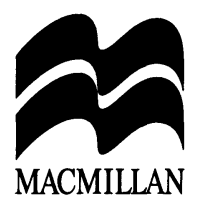


(C) Jan Wiener and Mannie Sher 1998

Foreword (C) Andrew Elder 1998

Foreword (C) Bonnie Sibbald 1998

All rights reserved. No reproduction, copy or transmission of this publication may be made without written permission.

No paragraph of this publication may be reproduced, copied or transmitted save with written permission or in accordance with the provisions of the Copyright, Designs and Patents Act 1988, or under the terms of any licence permitting limited copying issued by the Copyright Licensing Agency, 90 Tottenham Court Road, London W1P 9HE.

Any person who does any unauthorised act in relation to this publication may be liable to criminal prosecution and civil claims for damages.

The authors have asserted their rights to be identified as the authors of this work in accordance with the Copyright, Designs and Patents Act 1988.

First published 1998 by

MACMILLAN PRESS LTD

Houndmills, Basingstoke, Hampshire RG21 6XS

and London

Companies and representatives

throughout the world

ISBN 978-0-333-65205-3

ISBN 978-1-349-13964-4 (eBook)

DOI 10.1007/978-1-349-13964-4

A catalogue record for this book is available from the British Library.

$\begin{array}{llllllllll}10 & 9 & 8 & 7 & 6 & 5 & 4 & 3 & 2 & 1\end{array}$

$\begin{array}{llllllllll}07 & 06 & 05 & 04 & 03 & 02 & 01 & 00 & 99 & 98\end{array}$

Copy-edited and typeset by Povey-Edmondson

Tavistock and Rochdale, England 


\section{CONTENTS}

Foreword by Andrew Elder

Foreword by Bonnie Sibbald

xiv

Acknowledgements

xviii

Preface

$\mathbf{X X}$

1 Hopes and Realities of Work in a Primary Care Setting

The growth of counselling in primary care

Why this growth? Implications of social change 3

A mixed response to counselling 5

$\begin{array}{ll}\text { Attractions of the work } & 7\end{array}$

The character of the setting 10

GPs and counsellors working together 12

Psyche and soma 13

Core discipline and patterns of employment $\quad 15$

Sessions in the surgery 16

$\begin{array}{ll}\text { Summary } & 17\end{array}$

2 The Doctor-Counsellor Relationship 18

$\begin{array}{ll}\text { Setting the scene } & 18\end{array}$

Models of teamwork in primary care 18

Styles of team membership $\quad 20$

Against teamwork 21

The wish for perfect care $\quad 22$

A new way forward 24

Advantages of counsellor attachments $\quad 24$

First steps 25

The developing relationship $\quad 26$

Relationships and work style $\quad 32$

Relationships: unity or fragmentation $\quad 32$

Problems in the doctor-counsellor relationship 33

Professional identity and teamwork $\quad 35$

Summary 39 
3 The Nature of the Work 40

Philosophies of work 40

Adapting to primary health care 41

What do patients expect from the counsellor? 43

Skills of the counsellor 44

Therapeutic modalities $\quad 45$

The counsellor as generalist or specialist $\quad 46$

The employment contract $\quad 47$

Practical requirements 48

Time management $\quad 49$

Summary $\quad 51$

4 Referrals: Who Really Needs the Counselling? 52

Referrals in a primary care setting $\quad 52$

The changing culture of referrals 53

The impact of government changes $\quad 54$

Enhancing the GP's attitude towards counselling $\quad 56$

When to refer? 58

Who to refer 59

Reasons for referral $\quad 60$

What do GPs expect from a referral? 61

What do counsellors expect from a referral? 62

Problems in the referral process $\quad 62$

Qualitative research into referral patterns 68

$\begin{array}{ll}\text { Summary } & 70\end{array}$

5 Assessment for Counselling and Treatment Options 71

Introduction 71

$\begin{array}{ll}\text { The metaphor of Janus } & 72\end{array}$

The aims of the assessment 73

Assessment in a primary care setting $\quad 74$

Who is assessed? $\quad 76$

$\begin{array}{ll}\text { Appropriate referrals } & 77\end{array}$

Inappropriate referrals $\quad 78$

$\begin{array}{ll}\text { Making the assessment } & 79\end{array}$

Assessment and treatment $\quad 80$

Recommendations for treatment $\quad 85$

Counselling options $\quad 86$

$\begin{array}{ll}\text { Summary } & 90\end{array}$

6 Ongoing Work in Primary Care 91

A psychodynamic approach towards ongoing work 91

What exactly are we doing? 91 
Struggles towards teamwork $\quad 93$

Counselling and ethnicity 98

Revisiting the practice: 'the revolving door' 102

Working with couples: who has the problem? 104

Brief therapy: a life audit 107

Supportive counselling: 'asking for what you need' 108

$\begin{array}{ll}\text { Summary } & 110\end{array}$

7 Psychosomatic Illness: the Path towards a Common

Language

The language of the body 111

What is psychosomatic illness? 111

Somatisation and psychosomatic illness 113

A psychodynamic understanding of psychosomatic illness

Psychosomatic illness and hysteria $\quad 115$

Psychosomatic illness in primary care 117

Who is treatable? $\quad 118$

Ways of working together 124

Summary $\quad 125$

8 Key Professional Issues $\quad 127$

The changing professional culture of primary care $\quad 127$

Interprofessional relationships $\quad 127$

Liaison with other disciplines 128

$\begin{array}{ll}\text { Confidentiality } & 129\end{array}$

Funding psychological services 133

Communication $\quad 135$

Employment and accountability 137

Group dynamics 138

Leadership and authority 141

Summary 142

9 Does Counselling Work? 143

How to evaluate counselling? 144

Redefining the problem 147

The cost-effectiveness of counselling $\quad 150$

Summary: the way ahead $\quad 155$

Appendix A: Key Terms and Concepts 157

Introduction 157

Unconscious processes $\quad 158$

Mechanisms of defence $\quad 158$

$\begin{array}{ll}\text { Projective identification } & 160\end{array}$ 
Institutional defences 161

Transference and countertransference 163

Working with opposites $\quad 164$

Systems theory 166

Appendix B: Professional Training for Counselling in Primary Care 168

GP Training 168

Training for Counsellors $\quad 168$

Joint Training for GPs and Counsellors 169

Appendix C: Addresses of Organisations Interested in Counselling in Primary Care 170

References 172

$\begin{array}{ll}\text { Index } & 179\end{array}$ 


\section{FOREWORD}

\section{Andrew Elder}

General practitioners are often rather modest about their counselling skills, pretending they know little about counselling and its expertise; but over the years in practice they have usually gained an extensive knowledge of life through witnessing a vast range of different people's reactions to living. This body of experience, with its related set of listening skills can easily get overlooked, particularly in an atmosphere where there is an over-reliance on the more measurable aspects of medicine. But if it is more fully recognised, it can quickly be seen that this aspect of general practice and a psychodynamic approach to counselling (and psychotherapy) are likely to be productive allies. Both are concerned with human development, difficulties in relationships, and with disturbing emotions, pain and distress, but also with the idea that growth and greater resourcefulness can arise out of emotional difficulty. Both are also concerned with the unfolding of longer-term narratives of life, for therapists seen through a window of regular sessions designed to foster an understanding of a person's inner world, and for general practitioners seen through a window of episodic appearances in their consulting rooms for illness and emotional distress, as well as through observing individual patterns of seeking help.

General practice is changing rapidly, but the central difficulties of practising medicine will remain the same: the core continues to be an encounter with suffering and mortality, within the limitations set by a human relationship. This is intensified in general practice, with the inclusiveness of its contract with the patient and the possible timescale of commitment, which can give rise to heavy responsibilities for the GP to carry. Clinical techniques continue to improve, medical organisations develop, and the patterns and emphasis with which professional resources are deployed and change; but all these developments are potentially double-edged. Do we use them to help us perform a difficult task more effectively, or avoid it more easily? 
As the responsibilities increase for GPs and primary care teams, each member of the team needs to grow in depth and awareness of the contribution that is made by others. GPs have not been good at this, particularly when relating to professionals outside the medical fold. There is still a need for us to relinquish the ' $I$ can do it all' mentality and learn more about what our colleagues have to offer. This is the only way to prevent teamwork becoming fragmented, and the authors present an excellent model in cross-professional thinking which should help GPs understand much more about the origins, attitudes and aims of counselling. Good medicine and psychodynamic psychotherapy (or counselling) both involve getting to the heart of a problem with someone, and not necessarily taking a long time to do so.

As the authors point out, there has been a steady growth of interest, from the late 1960s onwards, in bringing these two worlds closer together; exploring what the two disciples can bring to each other, and examining the difficulties encountered, because of course there are tensions and differences of approach as well as similarities. To what extent does a therapist become included in shared clinical or organisational thinking within a practice? Welcomed? Or apparently valued but always forgotten about? How is the sharing of information dealt with? Can a sufficiently common language be found to discuss some of the ambivalence and complexities of feeling that tend to cluster around referrals, as well as allowing worthwhile discussion about different roles and an honest formulation of aims?

Until about ten years ago, it was still a relatively small number of practices that employed counsellors or psychotherapists, and they were mainly practices with an already evident interest in a psychological approach to medicine. The number of counsellors working in practices has mushroomed in recent years, and the authors make a number of interesting points about this. The reasons have included the influence of the internal market and the moves to a more primary care based health service, as well as the growth of training in counselling, and (still the most important) the continuing need to bring psychotherapeutic help closer to where most people are likely to be able to benefit from it, when they need it.

Given this longish period of time during which the subject has been developing, and the likely rich potential for therapeutic work in primary care, it may come as something of a surprise that there has not been a comprehensive book of this sort before. But it has been worth waiting, because we do now have a book that has been 
written from a durable acquaintance with the setting, and from two highly trained analytical psychotherapists who have a real respect for the work, and who were among the first generation of brave therapists who took their skills out into the GP market-place. They have both been involved in teaching and writing about the opportunities presented by GP work for many years. The extent to which they draw on a wide range of psychoanalytic ideas (Feud and Jung in an unusually happy combination), along with concepts drawn from systems theory and organisational consultancy, and the depth with which they are able to relate them to their subject, will not be equalled.

Often in a general practice we are too tightly focused on the immediate and the physical, and less able to shift our focus sufficiently to see other longer-term patterns and feelings unfolding. This tension is ever present in the consulting room, but it is also present in the way the discipline itself is evolving: at one moment seeming to recapture a sense of security by focusing predominantly on an intellectual agenda set within conventional medical lines, and at other times able to be more adventurous and embrace new ways of looking at its work through the eyes of another discipline. There is much in medicine that cannot be illuminated by medicine alone. When psychotherapists and GPs work together both should be changed as a result and learn from each other. It is not helpful if doctors use counsellors in order to retreat to 'proper medicine'. Even if some doctors want to do that it does not work, because counsellors can only ever see a fraction of the patients who come to doctors with problems connected to their emotional lives. Such doctors are often mistrustful of theory and what they see as 'soft knowledge', preferring action to talk. The world of counselling will seem foreign to such doctors, and the authors have been wise to use frequent case illustrations which do not allow the text to stray too far into theory, and have the effect of keeping the discussion well-anchored in the recognisable (and always interesting) world of GP surgery problems. This makes it a GP-friendly introduction to the subject for those naturally sceptical GPs.

Just as our understanding of general practice as a discipline continues to evolve as we learn more about the strengths and limitations of our setting, perhaps the same will happen to counsellors and psychotherapists who come to work with us. Doctors start out in general practice with a carefully made bag of skills and knowledge prepared for them in a specialist setting (hospital-based medical schools), and then when they arrive in a surgery they have 
to begin to adjust, abandoning some things, learning others, until they succeed in finding a way of being a personal doctor in a truly generalist setting. The task for specialists is to be expert within a restricted field, and it can be painful to give up some of the special things that are gained by this, but for some people (not all) other things emerge as a result which make it worthwhile. It will be interesting to see to what extent this process occurs for psychotherapists in primary care. Will a new and distinct generalist-type primary care therapist begin to appear, with a carefully structured training to match? As the authors point out, it is misleading to think of this as simple work, requiring little in the way of training. The range of patients encountered, the often-complicated surrounding network of professional relationships, the impact of chronic and serious physical illness, and the need for flexibility and responsiveness to the less regulated and often anxiety driven environment in primary care, all make it a demanding place to work. And if you are going to set sail in a rough sea, you need a well-made craft to carry you. How should it be constructed? For the future I would hope that therapists in practice might have had a well-internalised primary training which has included some experience of working in primary care, before then participating in a programme of further training which focuses on the special aspects of the setting, and subsequently to be able to be part of a continuing and supportive professional network of therapists and doctors too. As is apparent from Appendix B, (Professional Training for Counselling in Primary Care) there is still more or less no further training available for therapists wanting to work (or for those who are already working) in general practice.

It is clear from the authors that this is an exciting new arena for highly effective therapeutic work. And it is largely uncharted territory. Stimulated by reading this book, I found myself wondering whether we have all been rather slow in realising that this is more than simply a change of place for counsellors (or psychotherapists) to locate themselves, but something rather more interesting than that, a move that could pave the way for a distinctive new discipline with accompanying research interests and clinical expertise? Jan Wiener and Mannie Sher have done an excellent job, but let us hope it turns out to be a foundation-stone raising as many questions for the future as it answers, and paving the way for more detailed studies of the many different aspects of this work to which the authors have shown the way.

For instance, in the light of recent research into the later effects of parent-child interaction arising from attachment theory, should we 
be beginning to think more about primary care work with children, and with mothers and infants? How can we examine further the effects on psychotherapeutic work of the containing function of a practice? Is there a greater intensity of therapeutic contact possible in the relatively brief but repeated series of sessions in primary care than would be possible in other settings or private practice? In what ways can therapeutic work adapt itself in order to take full advantage of the nature and timescale of the GP setting?

This question is urgent, because of the present unfortunate dominance of the time-limited, six session models, which completely run against the open-door nature of work in general practice, and tend to be driven by anxieties about unlimited need. What can we learn from patients who are unlikely to see a therapist in any other setting? Similarly, what becomes possible because of the opportunity for collaborative work? If there is a sense in which a practice can become a secure base, should we begin to consider the therapeutic (as well as research) implications of the characteristics of a patient's attachment relationship to the practice? And there must be many ways in which we can extend our understanding of psychosomatic medicine. In other words the clinical parameters of work in this setting are still to be defined, and the process is likely to continue generating many interesting questions. Let us hope that the culture of general practice evolves in such a way that undertaking studies of this sort will become more rather than less likely.

We need combined exploration: doctors and therapists together. Both will be the richer as a result. Patients will benefit too. The role is now an established one and the figures show a large number of therapists already working in practices. The time is ripe for more examination of the work, and proper training and research. This book is likely to give the whole subject a major boost, and I welcome it. 


\section{FOREWORD}

\section{Bonnie Sibbald}

The general practice setting is one of the most challenging environments in which to provide counselling. As the principal providers of primary health care, general practice teams offer first contact, ongoing and comprehensive health care to people irrespective of their age, sex or presenting health problem. A very high proportion of the people presenting in general practice have emotional or psychological difficulties enmeshed within a complex tangle of physical and social problems. The health care team's job is to help people make sense of this undifferentiated distress and dis-ease, and formulate a strategy that will foster a return to health and well-being. Counsellors can play an enormously valuable part in this process, but to do so they need to appreciate the special opportunities and limitations of working in primary care teams. Equally, primary health care professionals need to understand and value the counsellor's role if the team as a whole is to work effectively in maximising health outcomes for patients.

The authors, both experienced psychotherapists in primary health care, thoroughly understand and bring alive the special circumstances of work in the general practice setting. They aptly liken general practice to a souk or bazaar in the richness and complexity of presenting problems, the high emotional tension and the absence of firm boundaries. Counsellors new to general practice will find this book helps them make sense of the 'souk'. The culture of general practice, the nature of the doctor-counsellor relationship, and the opportunities and limitations of work in this setting are explained and richly illustrated with case material. For their part, general practitioners and primary health care nurses will find the book offers an invaluable insight into how counsellors work with clients, the philosophies underpinning their approach to health care and the benefits they seek to bring to patients. The insights gained should enable each professional better to understand and appreciate 
the other's role, so enabling them to work more effectively together for the good of the patient.

The early chapters deal with the evolution of counselling services in general practice settings, the emergence of different models of employment, and how this has shaped the nature of counselling service provision. The history illustrates how the development of counselling services in general practice is intimately bound up with the development of general practice itself. National Health Service policy changes over the past two decades have given general practitioners more power to shape the skill mix of their teams by employing or commissioning other health professionals to work with them in the practice. This, together with wider social and cultural changes fostering a more holistic approach to care, has fuelled a massive expansion in general-practice-based counselling services. General practitioners for the most part now practice in large multidisciplinary teams, of which counsellors are a valued and integral part.

Good multidisciplinary team working is an essential part of good primary health care. The authors see effective team working between counsellor and general practitioners as particularly valuable in that it may compensate for fragmentation of life in society by integrating physical with psychological care. Particular attention is therefore given to the nature of the doctor-counsellor relationship. Through their case material and astute observations, the authors reveal the complexity of these relationships and their implications for patient care. Some doctors are uncomfortable dealing with the emotional and psychological needs of patients and need the counsellor to relieve them of this burden. Others regard emotional care as integral to the work of the general practitioner and may be reluctant to see others take over this aspect of their work. Still others recognise that their skills and time are limited and greatly value the assistance of a skilled mental health professional in managing their workload. Tensions in their personal lives mean that all doctors may sometimes make referrals to the counsellor that reflect their own needs more than those of their patients. The counsellors must maintain a delicate balance between flexibility in responding to these differing needs and firmness in maintaining their own space and identity so that patient care is effectively and appropriately directed. It becomes clear that the doctor-counsellor relationship defies stereotyping as it reflects the emergent understanding of two people engaged in learning about each other's skills and working practices. Jan Wiener and Mannie Sher show how 
counsellors and general practitioners may go about setting the ground rules for their relationship and then build on this foundation to achieve an effective working alliance.

General practice offers counsellors the opportunity to work with a wide range of psychopathologies and engage clients at an early stage, so preventing progression to more serious or entrenched problems. However the time constraints and imperatives of primary care make it generally inappropriate for counsellors to engage in long-term therapy with all but a few clients. Brief therapy provided over no more than six sessions is typical in general practice settings. Counsellors therefore have to be highly skilled in patient assessment, able rapidly to appraise patients' problems and formulate a suitable course of action. Assessment is arguably the most important role of the counsellor in general practice settings and it is entirely appropriate that Jan Wiener and Mannie Sher devote a whole chapter to this issue.

They identify six main aims of the assessment of process - three of which deal with understanding the patient's problem and formulating a treatment plan, and three of which deal with integrating the patient, the problem and the treatment plan into the wider context of the general practice. It is here that the authors' combined expertise in psychodynamic approaches, which emphasise the two-person relationship, and systemic approaches to organisational behaviour, which are able to locate this dyad within a larger network of relationships, is most telling. They show how the doctor-patient relationship shapes the nature of referral to the counsellor; how the counsellor-patient relationship may be used to understand the true nature of the patient's problem; and how the resources and relationships within and outside the practice shape the treatment options available. The chapter integrates and brings into sharp focus the material presented in earlier chapters on the nature of counsellors' work, working arrangements and relationships within the primary care team.

The final chapter of the book is devoted to a consideration of the value and cost-effectiveness of counselling in general practice settings. Counsellors, their clients and their general practitioner colleagues have few doubts that counselling is of benefit to many people. The problem arises in defining the nature of the benefits, estimating the costs of attaining the benefits, and demonstrating that counselling offers bigger health gains per pound invested than alternative forms of care provision. This is a tall order and research into these issues is still in its infancy. General practitioners and 
counsellors eager to defend the development of counselling services have pointed to potential cost savings in reduced prescriptions for psychotropic drugs, reduced off-site referral rates to specialist psychiatric services, reduced patient consultation rates and reduced patient relapse rates, to mention but a few. None of these claims have yet been proved, and there is growing evidence against several of them. The defenders of counselling services frequently express anger and frustration with health service researchers for their focus on these measurable and arguably peripheral aspects of service provision. In so doing they forget that they are themselves the authors and advocates of these claims. Counsellors, clients and general practitioners alike need to reflect more carefully on the fundamental benefits of counselling, which surely lie in the personal growth and development of clients. It may well be that these benefits are not 'measurable', but it does not follow that they defy description or valuation. In this respect the authors' call for more and better qualitative research into the counselling process is both timely and appropriate.

BONNIE SiBBALD

Reader in Health Service Research National Primary Care Research and Development Centre University of Manchester 


\section{ACKNOWLEDGEMENTS}

This book would never have moved beyond its conception without the many patients we have seen and tried to help. What we have learned from them, through their willingness to entrust us with their distress and their very individual narratives, forms the cornerstone of the ideas embodied in the text of our book. It is these men, women and children whom we would like to acknowledge first.

Our very special thanks go to Alexis Brook and Jane Dammers, as well as to Mary Barker, Catherine Crowther, Roger Higgs, Robert Gosling, Cecile Muller, Joan Schachter, Jane Temperley and Pierre Turquet, whose wisdom, teaching and support as colleagues and friends over many years have helped the seeds of this project to germinate and grow.

Over the years we have worked with different doctors, psychotherapists, counsellors, researchers and supervisees, all of whom are committed to the development of counselling in primary health care and collaborative work between professionals from different disciplines. We would like to thank the following colleagues: Rachel Adema, Monica Bard, Beatrice Bartlett, Ruth Berkowitz, Anna Brave Smith, Mary Burke, Maureen Chapman, Seok Mee Chua, Geralyn Collins, Clare Corbett, Christopher Cordess, Steven Curson, Gareth Dee, Jan Dereham, Andrew Elder, Brian Fine, Esther Fonseca, Antony Garelick, Haru Ghadiali, Hilary Graham, Raymond Ho, Joan Hutton, Georgia Lepper, Patrick Keane, Patrick Kiernan, Ciaran Kilduff, Tim Ladbrook, Christine Manzi, David Mazure, Barbara McKenzie, Carmel Mond, Helen Muller, Teresa Pawlikowska, Christopher Perry, David Poole, Anne Robinson, Claudette Rosen, Jane Rosoman, Julia Ryde, Sharon Schamroth, Pury Sharifi, Maureen Sheehan, Bonny Sibbald, Bill Smith, Norah Smith, Sam Smith and Jill Walker.

More personally, we offer our special gratitude to Jane Haynes, Judith Hubback, Judy Goodkin and Gordon Lawrence, who gave us the confidence to begin to write, to Stephen Frosh for his intelligent 
and thorough editing and to Frances Arnold at Macmillan for supporting the idea. To our families and close friends, in particular Steven Kennedy and Leonie Sher, who had to endure our frequent absences and extreme mood swings during the gestation and birth of the book, we offer grateful thanks for their patience.

Last, but by no means least, we are also grateful to Jonathan Barker for his skill in guiding non-technological psychotherapists through the mazes of computer technology and for his forbearance in correcting ever-changing words and sentences, and to Susan Lucks for her administrative support.

The author and publisher are grateful to Oxford University Press for granting permission to quote from Jan Wiener and Jane Dammers' chapter in Jane Keithley and Geoffrey Marsh (eds), Counselling in Primary Health Care (1995), to the Journal of Analytical Psychology for extracts from Jan Wiener's article 'Looking out and looking in: some reflection on "body talk" in the consulting room' (JAP, vol. 39, no. 3), and to Routledge for extracts from Jan Wiener's chapter in Ian Alister and Christopher Hauke (eds) Contemporary Jungian Analysis: Post-Jungian Perspectives from the Society of Analytical Psychology (forthcoming). 


\section{Preface}

When beginning to read a book on counselling it is helpful to have an understanding of where the authors are coming from: their background training and interests; belief systems and models of work; theoretical orientation and prejudices as well as their clinical experience. All these have inevitably affected the content and style of the book.

Although we come from different backgrounds - Jan Wiener is a Jungian analyst and research psychologist - and Mannie Sher is a psychoanalytical psychotherapist and organisational consultant we both have experience of working in similar settings, including the National Health Service, primary care, industry and private practice, and in many ways our skills and experiences are complementary. We hope that, as a team, we have sufficient in common in terms of our attitudes to work in primary care to give a coherence to the central themes in the book, while at the same time sufficient difference to incorporate our own specialisms and particular areas of expertise. A central common experience is that we have both worked as psychotherapists in GP practices for over fifteen years, and it is from our psychological and political commitment to the benefits and exciting opportunities for developing counselling and psychotherapy in primary care, that the energy and motivation to write this book has been generated and sustained over a two year period. Jan Wiener brings particular interests in assessment for counselling and psychotherapy and in the psychodynamics of psychosomatic illness; Mannie Sher brings expertise in the areas of group dynamics and organisational behaviour.

The book is predicated on a psychodynamic approach that places great value on the role of unconscious forces in the shaping of both individual and collective attitudes and behaviour. We believe it likely that the context and general character of primary care fundamentally determine the kind of work that goes on with patients and the dynamics of interpersonal relationships within 
the primary care team. The challenge for counsellors working in this field lies in trying to combine two approaches: a psychodynamic approach, where the privacy of the two-person relationship between a patient and counsellor is respected, and a systemic understanding of organisational behaviour, as the patient-counsellor dyad is likely to constitute only one part of the network of relationships in the practice as a whole. A systems approach is concerned with how systems influence the delivery of care. Counsellors need to relinquish some of their private practice dictums, which are emphasised in many training courses, if they are to adapt successfully to the work. They need to become more flexible about the models of work they use, their techniques, responsiveness and boundaries of confidentiality.

This book also places considerable emphasis on an object relations approach, where relationships between people in the practice are highly valued. The quality of the relationship between GP and counsellor has a critical effect on the nature of the work with patients, and this relationship is in turn affected by the power of the patient. In an environment where action predominates and where quick decisions are often necessary, our approach advocates a space for thinking and reflecting about what is happening inside the patient, the GP and the counsellor, as well as between them and within the practice as a whole. Many psychodynamic concepts, developed originally by Freud, Jung, Klein, Winnicott, Bion and others, can be very useful in helping counsellors to understand these relationships more profoundly, particularly if they are looked at in the context of personal and institutional defence mechanisms. This understanding, involving time to consider 'what things mean', can lead to better decision making and improved patient care, and constitutes the fulcrum of the approach that is developed in the different chapters of this book.

We hope we have produced a book that is useful for primary health care professionals with an interest in counselling, its appropriateness for patients, its benefits, pitfalls and the different ways in which it may be incorporated into practices. We have written it with the expectation that counsellors, psychotherapists, GPs, psychologists, community psychiatric nurses, health visitors, practice nurses and practice receptionists will all find something to interest them. Whilst an increasing number of papers on counselling in primary care are now being written, the existing literature is generally thin. East (1995) and Keithley and Marsh (1995) have produced valuable texts on the subject, but this is the first single volume to develop the 
principles and practice of counselling in primary care from a psychodynamic point of view.

We do not intend that the book should be read from start to finish. Each chapter is complete in itself and we have cross-referenced topics that appear in different chapters. When learning about any subject there is usually a dialectic between theory and practice, and although our brief was to produce a 'practical' text on counselling in primary health care, as all good practice is underpinned by appropriate theory we have included relevant contemporary psychoanalytic theory that will be useful to the practitioner. A glossary of terms appears in Appendix A at the end of the book. We have included many case examples in all chapters in the hope that this will bring the nature of the work to life. All names and some personal details have been disguised to protect the identity of our patients.

The term 'counsellor' is used throughout, although we are aware that many people working in primary care will be trained as psychotherapists or psychologists and that many counsellors bring the values of psychotherapy and a psychoanalytic approach to their work. Our view is that a psychodynamic approach to individual and institutional work can build a bridge between the fields of counselling and psychotherapy and may be theoretically and clinically useful for both. Similarly, we use the word 'patient', although we know that for many counsellors the designation 'client' is better suited to the nature of their relationship with the people with whom they work.

Debates about the differences between counselling and psychotherapy are commonplace and can become heated. Definitions of counselling range from the generic, which argues in favour of the 'deprofessionalisation of counselling' so that its methods may become widely available, to the narrower definitions in popular use, including 'counselling as advice' and 'counselling in psychological and social care' (Bond, 1995). This latter usage comes closest to the approach developed in this book, where we emphasise the use of the relationship between a trained counsellor and a patient as the central method of facilitating personal growth in the patient.

The BAC (1993, p. 1) also defines counselling in this vein:

the overall aim of counselling is to provide an opportunity for the client to work towards living in a more satisfying and resourceful way. The term 'counselling' includes work with individuals, pairs or groups of people, often, but not always referred to as 'clients'. The objectives of particular counselling relationships will vary according to the client's 
needs. Counselling may be concerned with developmental issues, addressing and resolving specific problems, making decisions, coping with crises, developing personal insight and knowledge, working through feelings of inner conflict or improving relationships with others. The counsellor's role is to facilitate the client's work in ways which respect the client's values, personal resources and capacity for self-determination

The task of differentiating between counselling and psychotherapy is almost impossible, given the many different meanings that are attributed to both terms, as well as the overlap between them. From the inside of the profession looking out, it is probably true to say that we are talking about differences in training, both in approach, where different trainings emphasise and teach different skills, and in intensity, where the length of time, frequency and depth of personal therapy may vary. From our own perspective, it is often the degree of deprivation in the patient's early life and the stage of developmental failure that determine whether counselling or psychotherapy is more appropriate. Although both of us have undergone similar training, and subscribe to a similar approach to working with people in distress, we bring our own perspectives to the job. Struggling to make distinctions in meaning between terms takes us into stormy waters, where the rivalries and status positions among different training organisations can seriously interfere with clarity of thinking. As Bond (1995, p. 7) helpfully points out:

there is no universally accepted distinction between the terms 'counselling' and 'psychotherapy' . . . there are well-established traditions which use the terms interchangeably. On the other hand, the terms are sometimes used in ways which distinguish them from each other.

The BAC (1993, p. 2) acknowledges that:

a number of differently qualified professionals may fulfil the role of a 'counsellor' in a general practice. These include: counsellors, psychotherapists, nurses, doctors, chartered psychologists and social workers ... who will bring a variety of different professional skills to the role.

This book applies a psychodynamic approach to work in primary health care and will be of interest to both counsellors and psychotherapists who are psychodynamically trained. Attempts to differentiate between counsellors and psychotherapists in terms of their training may therefore be less relevant than attempts to ensure that professionals do not sail into waters beyond their personal training, skills and experience. Regular supervision of clinical work is likely to provide valuable assistance in recognising those pro- 
blems that can be worked with and those that require greater depth or intensity and a further referral.

At the moment the profession is putting an enormous amount of time and energy into regulating itself and providing national standards and ethical guidelines. The British Association of Counselling is a national body that is working on user guidelines about training standards for counsellors, so that prospective users may know enough about the background qualifications of the counsellors they see to trust that they are sufficiently well-trained. There are plans in motion to start a United Kingdom Register for Counsellors (UKRC). Within the field of psychotherapy there has been much progress towards regulation of the profession. The United Kingdom Council for Psychotherapy (UKCP), whose total membership is approaching 3600, now has a register of 75 organisations offering different types of psychotherapy. These organisations are classified into eight groups according to their approach, and there are stringent procedures for establishing basic standards and codes of ethics. Another organisation, the British Confederation of Psychotherapists (BCP), was formed in 1995 to take account of the more stringent training standards of some psychoanalysts, analytical psychologists and psychoanalytical psychotherapists, and now has twelve member organisations. The two umbrella organisations continue to exist side by side, and a number of psychotherapists belong to both. 